\title{
Differential expression of Snail1 transcription factor and Snail1-related genes in alveolar and embryonal rhabdomyosarcoma subtypes
}

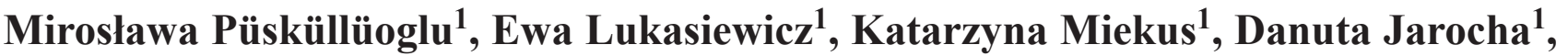 \\ Marcin Majka ${ }^{1}$
}

${ }^{1}$ Department of Transplantation, Polish-American Institute of Pediatrics, Jagiellonian University Medical

College, Cracow, Poland

\begin{abstract}
Rhabdomyosarcoma (RMS) represents the most common sarcoma of soft tissue among children. Two main RMS subtypes are alveolar (ARMS) and embryonal (ERMS). The major goal of this study was to find differentially expressed genes between RMS subtypes that could explain higher metastatic potential in ARMS and would be useful for the differential diagnosis. Using RQ-PCR analysis we compared expression of Snaill and Snail-related genes among 7 ARMS and 8 ERMS patients' samples obtained from the primary tumors and among 2 alveolar and 2 embryonal cell lines. Our results show that Snaill is highly expressed both in ARMS patients' samples and the alveolar cell lines. We also found that the expression of E-Cadherin was downregulated and the expression of Matrix Metalloproteinases 2 and 9 (MMP-2 and MMP9) was upregulated in ARMS. We assume that, as in many tumors, also in RMS Snaill acts as a regulator for pathways known for their role in cells' metastasis and that Snaill activity results in increased MMPs and decreased E-Cadherin expression. Our findings may explain higher ARMS aggressiveness. Moreover, we suggest that further studies should be performed to verify if Snaill can be considered as a potential target for ARMS therapy.
\end{abstract}

Key words: Snail1, rhabdomyosarcoma, ARMS, ERMS, E-Cadherin

\section{Introduction}

Rhabdomyosarcoma. Rhabdomyosarcoma (RMS) usually develops between the second and the fifth year of life and in adolescence. There are three subtypes of RMS. Two main are embryonal (ERMS) and alveolar (ARMS). The third one, uncommon among children, is pleomorphic. The two first subtypes constitute around a half of the soft tissue sarcomas among children and young adults [1]. There are important differences between ARMS and ERMS in clinical and histological picture on which the diagnosis is based. ARMS tumors have, in general, worse prognosis, and occur in older children and teenagers. Common locations for ARMS tumors are: extremities and trunk whereas for ERMS: head and neck and urogenital system [1]. Typical for

Correspondence: M. Majka, Dept. of Transplantation, Polish-American Institute of Pediatrics, Jagiellonian University, Wielicka Str. 265, 30-663, Cracow, Poland; tel.: (+4812) 6591593, fax.: (+4812) 6591594, e-mail:mmajka@cm-uj.krakow.pl part of ERMS tumors is loss of heterozygosity ( $\mathrm{LOH})$ of $11 \mathrm{p} 15$. It causes Insulin-like growth factor 2 (IGF2) overexpression and lack of H19- suppressor gen. In around $80 \%$ of ARMS tumors translocation $\mathrm{t}(2 ; 13)(\mathrm{q} 37 ; \mathrm{q} 14)$ or $\mathrm{t}(1 ; 13)(\mathrm{p} 36 ; \mathrm{q} 14)$ leads to Pax3FKHR or Pax7-FKHR fusion genes formation [2].

Snail 1 and epithelial-mesenchymal transition. Snail1 belongs to the group of conservative zinc finger transcription factors [3]. There are numerous processes on which Snail has a noticeable impact: cell proliferation, apoptosis and survival, cell cycle regulation, cell shape, movement, differentiation, gastrulation or mesoderm formation $[3,4]$. Particular role of Snaill has been described in the epithelial-mesenchymal transition (EMT) - the main mechanism responsible for the invasiveness and metastasis of neoplasm in the advanced stages. EMT can be modified by numerous growth factors such as fibroblast growth factor (FGF), hepatocyte growth factor (HGF), transforming growth factor $\beta$ (TGF $\beta$ ) [4] or by Notch pathway [5]. It has 
Table 1. Description of RMS cell lines.

\begin{tabular}{|l|l|l|l|c|}
\hline \multicolumn{1}{|c|}{ Cell line } & \multicolumn{1}{c|}{ RMS subtype } & \multicolumn{1}{c|}{ Established from } & \multicolumn{1}{c|}{ Fusion genes } & Literature \\
\hline SMS-CTR & ERMS & Relapse & no & 11 \\
\hline RD & ERMS & Relapse & no & 11 \\
\hline RH18 & ARMS or ERMS & Primary pelvic tumor & Pax3-FKHR or no & 12,13 \\
\hline RH30 & ARMS & Bone marrow metastasis & Pax3-FKHR & 14 \\
\hline
\end{tabular}

been suggested that most of these factors modify EMT through the genes belonging to the Snail family, e.g. by decreasing the expression of E-Cadherin [6]. Snail activation can also result in an increased expression of MMPs. Activity of Snaill remains under control of glycogen synthase kinase 3 (GSK3 $\beta$ ) - protein functioning as a part of $\beta$-Catenin degradation complex [7].

Factors considered to play a role in rhabdomyosarcoma metastatic behavior. The knowledge about the molecular differences between ARMS and ERMS is not complete. Different scientific groups proved the special role of fusion proteins Pax3(or 7)-FKHR and HGF-MET or chemokine pathways in higher ARMS metastatic behavior. The silencing of Pax3-FKHR reduces MET level. What is more, the induction of Pax3-FKHR in the embryonal cell line results in higher CXCR4 and MMP-2 expression [8,9]. The level of MMP-1, MMP-2 and MMP-9 expression has been shown to be higher in ARMS in immunohistochemical staining with no differences in the level of expression of Tissue inhibitors of Metalloproteinases (TIMPs) [10]. The way in which all these factors interact and the common point of this interaction have not been described.

In our studies we checked the expression of Snailrelated EMT- modulating genes. The results indicate different expression of these genes between RMS subtypes, which can modify the metastatic behavior of these subtypes.

\section{Materials and Methods}

Cell lines. The human rhabdomyosarcoma embryonal: SMS-CTR and RD and alveolar: RH18 and RH30 subtype cell lines were generously provided by prof. M. Z. Ratajczak (University of Louisville, KY, USA) and were grown at $37^{\circ} \mathrm{C}$ in Dulbecco's Modified Eagle's Medium (DMEM) (Gibco BRL, Grand Island, New York, USA) and supplemented with antibiotics, L-glutamine and $10 \%$ fetal bovine serum (Gibco). Cell lines are characterized in Table 1.

Material from patients. Paraffin embedded tissues contained samples of 15 RMS primary tumors. First group contained 7 patients with ARMS and the second 8 patients with ERMS. The patients were diagnosed in Polish-American Institute of Pediatrics in Cracow and selected according to the diagnosis of a primary tumor, the availability of material (paraffin embedded tissues), undoubted classification to histological subtype and the quality of isolated RNA.
Extraction of RNA and reverse transcription reaction. RNA from cell lines was isolated using RNeasy Mini Kit (Qiagen, Valencia, California, USA). Paraffin embedded tissues were cut into $10 \mu \mathrm{m}$-thick sections, then deparaffinized in xylene and rehydrated through a graded ethanol series. Tissues were digested with Proteinase K, then treated with TRIzol (Invitrogen, Carlsbad, California,USA). RNA was isolated using modified acid guanidinium thiocyanate-phenol-chloroform method [15]. cDNA was obtained from RNA by performing RT-PCR with random primers (Promega, Madison, Wisconsin, USA.) and Moloney murine leukemia virus reverse transcriptase (Invitrogen, Carlsbad, California,USA).

Real-time PCR. The expression of following genes in cell lines (50ng of cDNA/well) and material from patients (120 ng of cDNA/well due to lower quality of material received from paraffin-embedded tissues than from cell cultures) was estimated during real-time PCR (Applied Biosystems, Foster City, California, USA): Snail1 (Hs00195591 m1), Slug (Hs00161904 m1), Twist (Hs00361186_m1), $\beta$-Catenin (Hs99999168_m1), E-Cadherin (Hs00170423 m1), N-Cadherin (Hs00169953 m1), Met (Hs01565589_m1), Mmp-2 (Hs00234579_m1), Mmp-9 (Hs00234579_m1). The expression of HGF (Hs00300159_m1), Timp-1 (Hs00171558_m1) and Timp-2 (Hs00234278_m1) was checked only in the cell lines. Also the expression of the following genes (sequence of primers) was checked: Pax3-Fkhr (F 5'AAC CCC ACC ATT GGC AAT G, R 5'ACC CTC TGG ATT GAG CAT CCA) and Pax7-Fkfr (F 5'TTT GAG ACC CAC TAC CC, R 5'ACC CTC TGG ATT GAG CAT CCA). The control for probes was GAPDH (Hs99999905 ml) and the control for primers was $\beta$-Actin (F 5'GGA TGC AGA AGG AGA TCA CTG, R 5'CGA TCC ACA CGG AGT ACT TG). The reactions were performed in ABI PRISM 7300 Sequence Detection System (Applied Biosystems) with the use of TaqMAN PCR Master Mix (Applied Biosystems). The reactions with primers were performed with the use of Sybr Green PCR Master Mix (Applied Biosystems). $2^{-\Delta \Delta C T}$ method allowed calculating relative expression of genes.

Western blot. Total protein was isolated from cells using M-PER buffer (Pierce, Rockford, Illinois, USA) with proteases and phosphatases inhibitors (Sigma, St Louis, Missouri, USA). Nuclear fraction was isolated using NEB-B buffer (29 mM HEPES pH 7.9; $0.4 \mathrm{M} \mathrm{NaCl} ; 1 \mathrm{mM}$ EDTA; $1 \mathrm{mM}$ EGTA). Protein concentration was measured with EL800 detector and Protein Assay (Bio-Rad, Hercules, California, USA). Then electrophoresis on a sodium dodecyl sulfate-polyacrylamide gel (6 and $12 \%$ ) and transfer of proteins to polyvinylidene diflouride membrane (BioRad) was performed. Blot was incubated with $1 \%$ BSA for 1 hour and then overnight with primary antibodies: anti-SNAI1 1:1300 Sc-28199 (Santa Cruz Biotech., Santa Cruz, California, USA), anti-MET 1:1000 Sc-161 (Santa Cruz Biotech.) and GAPDH as a control 1:10000\# 2118 (Cell Signaling, Danvers, Massachusetts, USA). Secondary 1:5000 anti-rabbit IgG, antibody Sc-2054 (Santa Cruz Biotechnology) was conjugated with horseradish peroxidase. Proteins were visualized on 

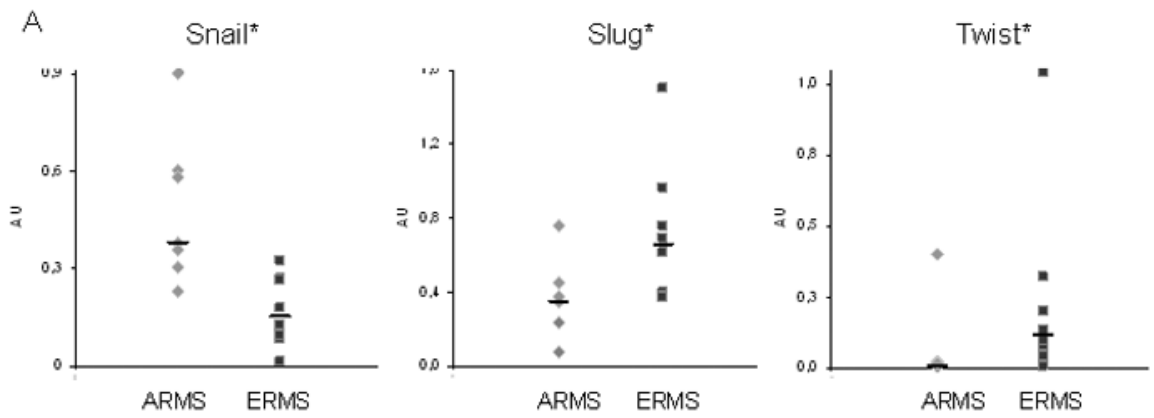

B

E-Cadherin

$\mathrm{N}$-Cadherin

$\beta$-Catenin*
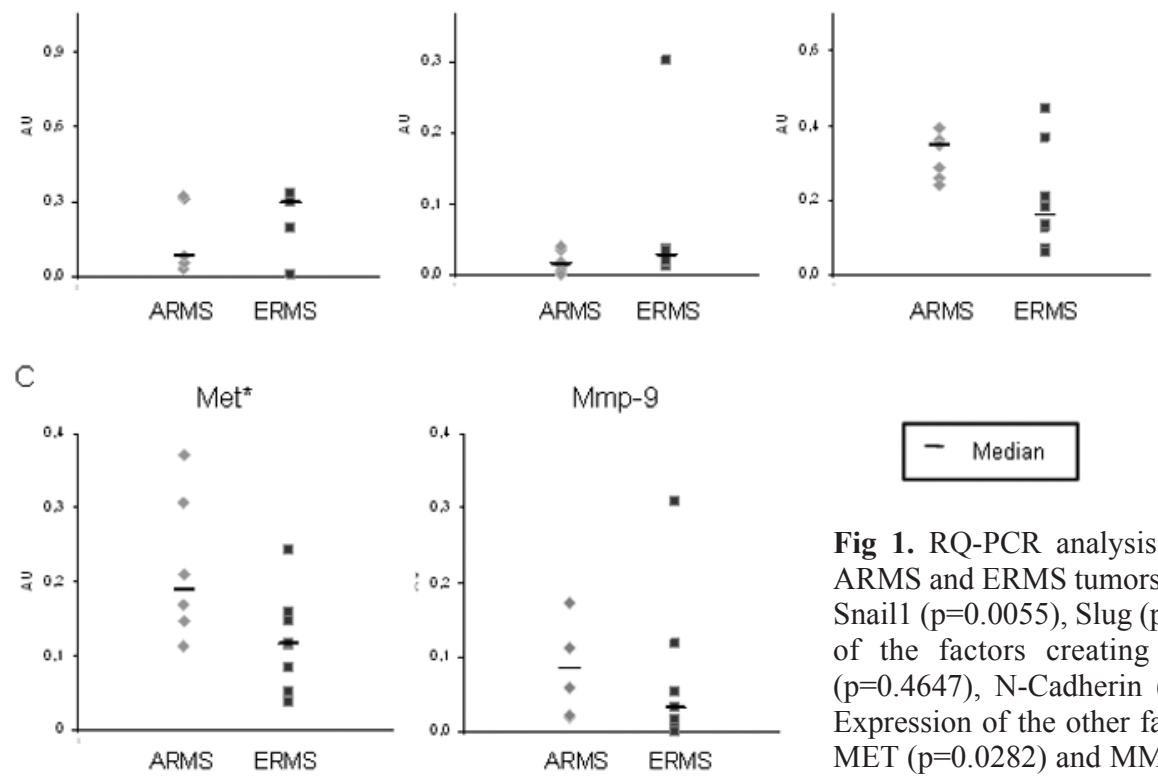

\section{- Median}

Fig 1. RQ-PCR analysis of mRNA in material from patients with ARMS and ERMS tumors. (A) Expression of the transcription factors: Snail1 ( $\mathrm{p}=0.0055)$, Slug $(\mathrm{p}=0.0372)$, Twist $(\mathrm{p}=0.0491)$. (B) Expression of the factors creating Cadherin-Catenin junctions: E-Cadherin $(\mathrm{p}=0.4647)$, N-Cadherin $(\mathrm{p}=0.1324)$ and $\beta$-Catenin $(\mathrm{p}=0.0491)$. (C) Expression of the other factors involved in the process of metastasis: MET $(p=0.0282)$ and MMP-9 $(p=0.2531),{ }^{*} p<0.05$.

photographic film (Amersham Life, Sciences, Little Chalfont, UK) using chemiluminescent reagent (Amersham Life).

Statistical analysis. Experiments for cell lines were repeated 2-4 times. In order to estimate the statistical difference between patients Mann Whitney U-test and between cell lines nonpaired TStudent test were applied. Correlations between genes were checked by fast regression analysis in Statistica 6.1 package.

\section{Results}

\section{The expression of EMT modulating genes in rhabdomyosarcoma subtypes}

Higher expression level of Snaill mRNA was detected in ARMS in comparison to ERMS subtype (Fig. 1A). These results were confirmed using established RMS cell lines. RH30 and RH18 alveolar cell lines had higher expression of Snail1 mRNA and protein level when compared to SMS-CTR and RD embryonal cell lines (Fig. 2A). In contrary the expression of Slug and Twist transcription factors was higher in ERMS tumors (Fig. 1A).

\section{Different expression of Snail1-related genes in rhabdomyosarcoma subtypes.}

Cadherins and MMPs are direct targets for Snaill. Thus we checked the expression of E- and N- Cadherins together with the expression of MMP-2 and MMP-9 in the patients' samples. The expression of both E-Cadherin and N-Cadherin was lower in ARMS in comparison to ERMS (Fig. 1B), but these tendencies were not statistically significant. Similar results were obtained for the cell lines (Fig. 3A higher expression of E-Cadherin in SMS cell line; Fig. 3B higher expression of N-Cadherin in both ERMS cell lines). We did not find any differences in MMP-2 expression in the primary tumors samples (data not shown). However, RH30 ARMS cell line expressed MMP-2 at high level (Fig. 3C). The expression level of MMP-9 was higher in ARMS tumor samples (Fig. 1C). MMP-9 was also highly expressed in RH18 ARMS cell line (Fig. 3D). No differences were visible in case of TIMPs (data not shown).

Next, we compared the expression of other genes involved in the metastatic process. $\beta$-Catenin expression 


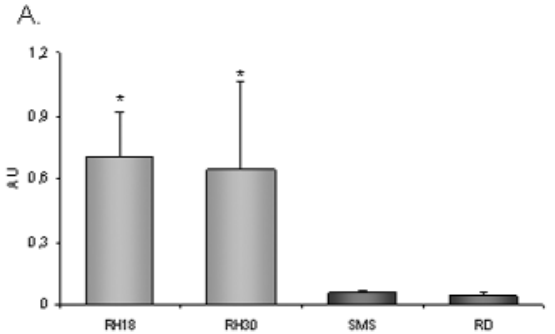

B.

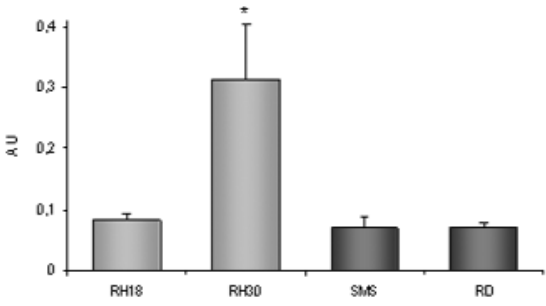

C.

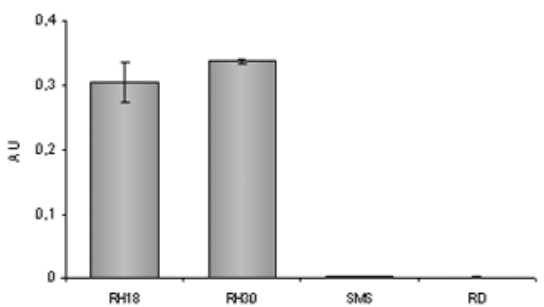

A
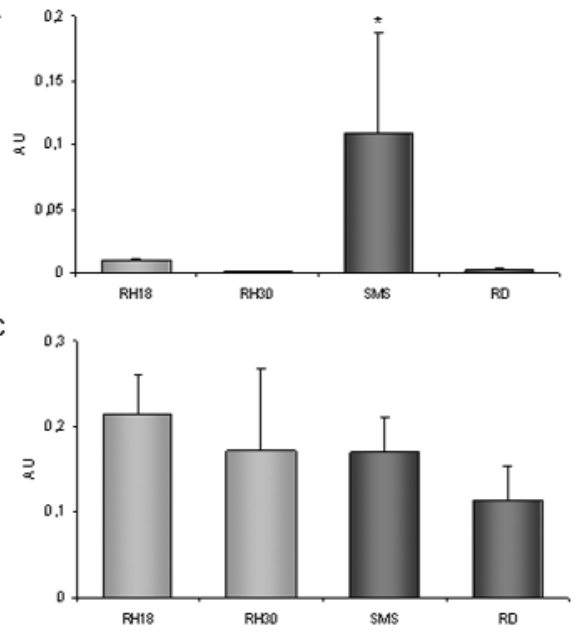
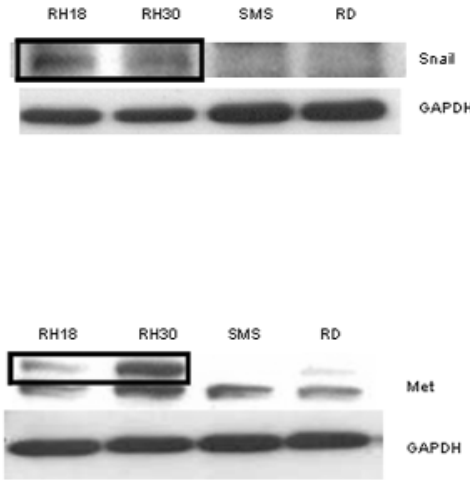

Fig 2. Results obtained for cell lines. (A) Snaill (RQ-PCR analysis of mRNA and Western blot analysis of nuclear protein level). (B) MET (RQ-PCR analysis of mRNA and Western blot analysis of total protein level). (C) Pax3-FKHR (analysis of mRNA level); ${ }^{*} \mathrm{p}<0.05$ when the expression of studied gene in this cell line is compared to the expression in any of two cell lines of other subtype.
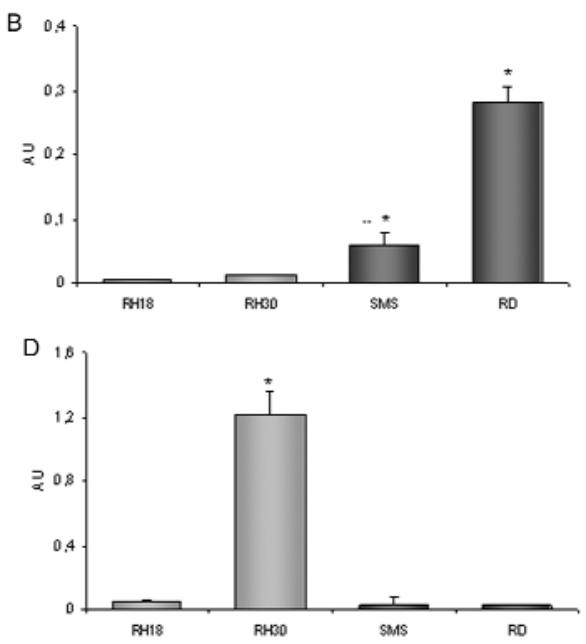

Fig 3. Results obtained for cell lines. (A) E-Cadherin; (B) N-Cadherin; (C) MMP-9; (D) MMP-2; (RQ-PCR analysis of mRNA). $* \mathrm{p}<0.05$ when the expression of studied gene in this cell line is compared to the expression in any of two cell lines of other subtype.

was noticeably higher in the tumor samples of ARMS subtype (Fig. 1B). We also confirmed the earlier reports that MET receptor expression is higher in ARMS than in ERMS tumors (Fig. 1C). This was again confirmed using RMS cell lines (Fig. 2B - higher expression on mRNA level in RH30 and on protein level in both alveolar cell lines). We did not see any differences in the expression of HGF (data not shown). This is probably due to very low expression of HGF in RMS (only detected using real time RT-PCR but not regular RT-PCR) that makes the interpretation difficult.
According to our results RH18 and RH30 cell lines have high expression of Pax3-FKHR on mRNA level, which is typical of fusion-positive ARMS (Fig. 2C).

\section{Correlation between the expression of Snail and the other genes}

The scrutiny of the data obtained for the tumor samples revealed also some existing correlations between the expression of Snail and the other genes. The expression of this transcription factor was positively 

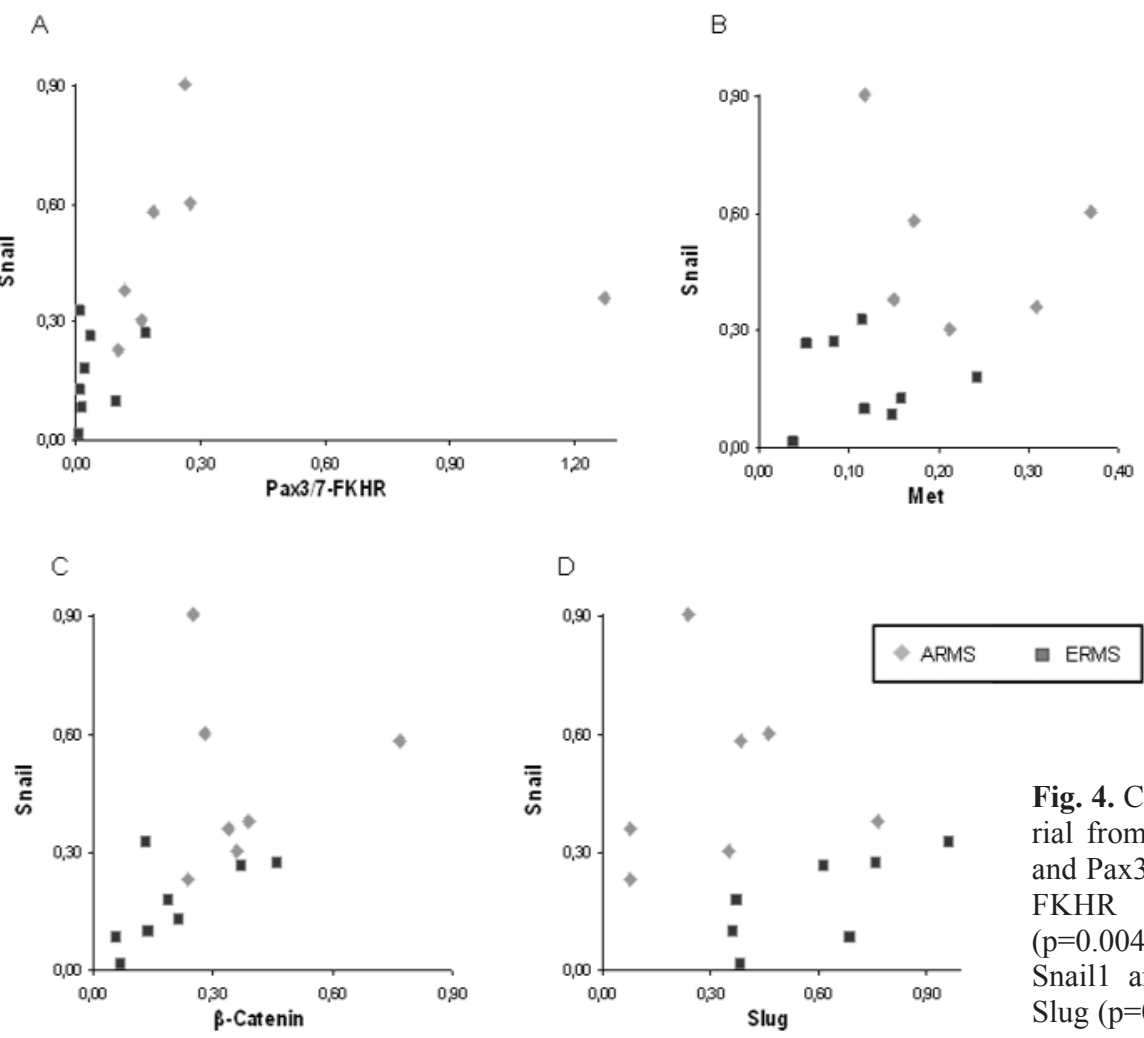

F. 4. Correlations between genes obtained in material from patients by RQ-PCR analysis. (A) Snaill and Pax3/7-FKHR (a sum of Pax3-FKHR and Pax7FKHR expression received for each patient) $(\mathrm{p}=0.0045) ;$ (B) Snaill and MET ( $\mathrm{p}=0.0019) ;(\mathbf{C})$ Snaill and $\beta$-Catenin $(\mathrm{p}=0.0045)$; (D) Snaill and Slug $(\mathrm{p}=0.0045)$.

correlated with Pax3(or 7)-FKHR (Fig. 4A) and MET receptor (Fig. 4B) expression. These proteins are well known for their role in the augmenting the metastatic behavior of ARMS tumors. Positive correlations were also seen between Snail1 and MMP-9 (data not shown) and $\beta$-Catenin (Fig. 4C). We observed a negative correlation between Snail and Slug (Fig. 4D).

\section{Discussion}

In this study we have observed the distinct expression of Snaill transcription factor and its related genes between rhabdomyosarcoma subtypes. The expression of Snaill positively correlated with the expression of Pax3(or 7)-FKHR fusion gene. This correlation can be a result of a direct regulation of Snaill expression by the fusion genes or an indirect through other proteins such as MET, which has been shown to play a role in regulating Snaill expression in other tumors [16] through phosphorylation of GSK3 $\beta$ and its inactivation. Thus, higher expression of Snaill might be explained by higher expression of MET in alveolar subtype (in RH30 cell line on mRNA level, in both alveolar cell lines on protein level and in patients samples). Interestingly, in case of RH18 alveolar cell line the expression of Snail1 is high and Pax3-FKHR fusion gene is present, but the mRNA level of MET is similar to this in embryonal cell lines. However, the level of
MET protein expression is similar to one observed for RH30 cells and this might again explain higher expression of Snail in this cell line. The lack of significant differences in the expression of HGF between ARMS and ERMS is also unexpected (data checked only in cell lines due to small amount of RNA received from tumor samples). One of the possible explanation is that highly expressed MET receptor might be activated not only in a result of HGF stimulation.

Approximately $20 \%$ of ARMS tumors do not possess the translocation [1]. Thus, expression of other genes could be responsible for highly metastatic phenotype of ARMS. We showed here that the expression of Snaill is higher in ARMS in comparison to ERMS patients' samples and this finding was confirmed using established cell lines.

We noticed that in ARMS tumors the expression of E-Cadherin is lower in comparison to ERMS and negatively correlates with the expression of Snail1. High E-Cadherin level is also noticed in SMS (but, surprisingly, not in RD) embryonal cell line. The decreased expression of E-Cadherin could be responsible for malfunction of cell-cell junctions in ARMS and higher ability of these tumors to leave the tumor bed and metastasize. We also noticed lower expression of NCadherin in ARMS. Since, the expression of E-cadherin is also regulated by other members of Snail-family e.g. Slug [17], it is possible that low E-cadherin 


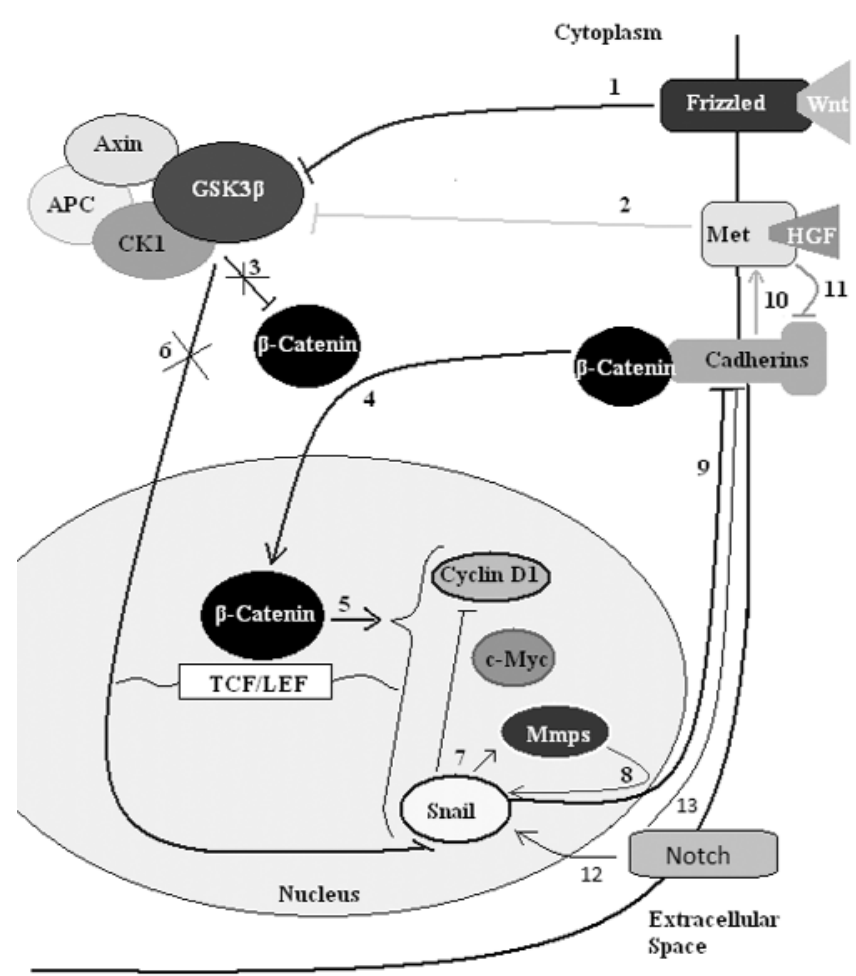

Fig. 5. Presumable interactions between factors responsible for ARMS higher metastatic behavior. Activation of Frizzled receptors by Wnts and MET receptor by HGF leads to phosphorylation of GSK $3 \beta$ protein $[21,24]$ and, the same, inactivation of $\beta$-Catenin degradation complex $(1,2)$. $\beta$-Catenin, freed from destructive influence of its degradation complex (3), is transported to the nucleus (4), where, acting through TCF and LEF nuclear proteins it can work as a transcription factor. High nuclear level of $\beta$ Catenin results in increased expression of its target genes e.g. Snail1 [25], MMPs, MET and Cyclin D1 (5). Phosphorylated form of GSK3 $\beta$ cannot inhibit Snail, which additionally promotes Snaill activity (6). Snaill itself increases the expression of other genes e.g. MMPs and inhibits Cyclin D1 [26] (7). Some of MMPs induce feedback activation of Snail1 (8). Snail represses Cadherins expression what frees $\beta$-Catenin from its associations with Cadherins and leads to MET internalization $(9,10)$ (as the presence of MET in cell membrane protein fraction depends on Cadherins presence [27]). Also MET has the ability of directing Cadherins to degradation pathway (11) [28]. The expression of Snail is also directly and indirectly up-regulated by Notch pathway (12), which was shown to play the crucial role in EMT process. Also E-Cadherin down-regulation requires Notch signaling (13) [5].

expression in RD cells is due to high expression of Slug. In case of RD embryonal cell line low E-Cadherin level may not indicate higher metastatic potential (similar to ARMS) because there is a high level of NCadherin detected in this cell line. N-Cadherin is responsible for creating normal cell junctions in muscular tissue [18]. Higher expression of N-Cadherin in ERMS subtype needs a further analysis.

MMPs were proved to be regulated by Snaill [19]. In our study we have shown that MMP-9 expression was higher in ARMS primary tumors and in RH18 cell line (established from primary change). Moreover, the expression of MMP-9 positively correlated with the expression of Snaill. RH30 cell line established from metastatic lesion had significantly higher expression of MMP-2 in comparison to other cell lines. There were no significant differences in the expression of MMP-2 between ARMS and ERMS primary tumors what may suggest important role of this gelatinase in aggressive late stage ARMS. Higher level of MMP-2 has already been attributed to ARMS subtype $[19,20]$.

$\beta$-Catenin was shown to interplay with Snaill in EMT facilitation [16,21]. In our research we have observed higher expression of $\beta$-Catenin in case of ARMS primary tumors. However, we have not observed any differences in $\beta$-Catenin expression in RMS cell lines. This discrepancy can result from the fact that SMS and RD cell lines were established from relapses where Wnt- $\beta$-Catenin pathway can play more significant role than in the primary ERMS tumors. Existing data suggest that the concurrent inhibition of Wnt- $\beta$-Catenin and HGF-MET axis decreases Snaill expression and restrains the growth of the soft tissue sarcomas [22,23]. We imply that the inhibition of Snaill itself, as a factor that links these pathways (and presumably other pathways and factors such as: Pax3(or 7)-FKHR, chemokine axis, MMPs), would intensify this effect (Fig. 5).

Other proteins proved to play an important role in EMT (i.e. by inhibiting E-Cadherin transcription) are Twist and Slug. Data regarding RMS tumors, in general, show high expression of Twist [29]. Twist inhibits factors responsible for miogenesis, such as MyoD [30] and increases N-Cadherin expression [31]. In our study the expression of Twist and Slug was lower in ARMS than in ERMS primary tumors. Using established cell lines, however, we did not confirm these results. LOH characteristic for many ERMS tumors has also been related to cell differentiation disorders. It has been shown that expression of Twist is higher among patients with $\mathrm{LOH} 11 \mathrm{p} 15$ than in other patients [32]. Expression of IGF-2 resulted from this LOH was also shown to influence the level of Slug [33].

In this paper we have shown for the first time that the distinction between RMS subtypes could be made on the base of the expression of Snail1 transcription factor. The expression of Snail1 is higher in alveolar subtype in comparison to embryonal in the patients' samples and this finding was confirmed using established ARMS and ERMS cell lines both on RNA and protein level.

Acknowledgments: This study was supported by research grant from the Polish Ministry of Science and Higher Education (N N401 229734), grant from Jagiellonian University Medical College $(\mathrm{WL} / 292 / \mathrm{P} / \mathrm{L})$ and The Adam Krzyzanowski Scholarship Found. 


\section{References}

[1] Parham DM, Ellison DA. Rhabdomyosarcomas in adults and children: an update. Arch. Pathol Lab Med. 2006;130:14541465.

[2] Scrable HJ, Witte DP, Lampkin BC, Cavenee WK. Chromosomal localization of the human rhabdomyosarcoma locus by mitotic recombination mapping. Nature. 1987;329:645-647.

[3] Nieto MA. The snail superfamily of zinc-finger transcription factors. Nat Rev Mol Cell Biol. 2002;3:155-166.

[4] Barrallo-Gimeno A, Nieto MA. The Snail genes as inducers of cell movement and survival: implications in development and cancer. Development. 2005;132:3151-3161.

[ 5] Sahlgren C, Gustafsson MV, Jin S, Poellinger L, Lendahl U. Notch signaling mediates hypoxia-induced tumor cell migration and invasion. PNAS. 2008;105:6392-6397.

[ 6] Lu Z, Ghosh S, Wang Z, Hunter T. Downregulation of caveolin-1 function by EGF leads to the loss of E-cadherin, increased transcriptional activity of beta-catenin, and enhanced tumor cell invasion. Cancer Cell. 2003;4:499-515.

[ 7] Zhou BP, Deng J, Xia W et al. Dual regulation of Snail by GSK-3beta-mediated phosphorylation in control of epithelialmesenchymal transition. Nat Cell Biol. 2004;6:931-940.

[ 8] Onisto M, Slongo ML, Gregnanin L, Gastaldi T, Carli M, Rosolen A. Expression and activity of vascular endothelial growth factor and metalloproteinases in alveolar and embryonal rhabdomyosarcoma cell lines. Int J Oncol. 2005;27:791-798.

[ 9] Libura J, Drukala J, Majka M et al. CXCR4-SDF-1 signaling is active in rhabdomyosarcoma cells and regulates locomotion, chemotaxis, and adhesion. Blood. 2002;100:2597-2606.

[10] Diomedi-Camassei F, Boldrini R, Rava L et al. Different pattern of matrix metalloproteinases expression in alveolar versus embryonal Rhabdomyosarcoma. J Pediatr. Surg. 2004:39:1673-1679.

[11] Kouraklis G, Triche TJ, Wesley R, Tsokos M. Myc oncogene expression and nude mouse tumorigenicity and metastasis formation are higher in alveolar than embryonal rhabdomyosarcoma cell lines. Pediatr Res. 1999;45:552-558.

[12] Gastaldi T, Bonvini P, Sartori F, Marrone A, Iolascon A, Rosolen A. Plakoglobin is differentially expressed in alveolar and embryonal rhabdomyosarcoma and is regulated by DNA methylation and histone acetylation. Carcinogenesis. 2006;27:1758-1767.

[13] Wysoczynski M, Miekus K, Jankowski K et al. Leukemia inhibitory factor: a newly identified metastatic factor in rhabdomyosarcomas. Cancer Res. 2007;67:2131-2140.

[14] Fredericks WJ, Galili N, Mukhopadhyay S et al. The PAX3FKHR fusion protein created by the $\mathrm{t}(2 ; 13)$ translocation in alveolar rhabdomyosarcomas is a more potent transcriptional activator than PAX3. Mol Cell Biol. 1995; 15:1522-1535.

[15] Godfrey TE, Kim SH, Chavira M et al. Quantitative mRNA Expression Analysis from Formalin-Fixed, Paraffin-Embedded Tissues Using 5' Nuclease Quantitative Reverse Transcription-Polymerase Chain Reaction. J Mol Diagn. 2000;2:84-91.

[16] Grotegut S, von Schweinitz D, Christofori G, Lehembre F. Hepatocyte growth factor induces cell scattering through MAPK/Egr-1-mediated upregulation of Snail. EMBO J. 2006;25:3534-3545.

[17] Bolós V, Peinado H, Pérez-Moreno MA, Fraga MF, Esteller M, Cano A. The transcription factor Slug represses E-cad- herin expression and induces epithelial to mesenchymal transitions: a comparison with Snail and E47 repressors. $J$ Cell Sci. 2003;116:499-511.

[18] Goichberg P, Geiger B. Direct involvement of N-cadherinmediated signaling in muscle differentiation. Mol Biol Cell. 1998;9:3119-3131.

[19] Miyoshi A, Kitajima Y, Kido S et al. Snail accelerates cancer invasion by upregulating MMP expression and is associated with poor prognosis of hepatocellular carcinoma. $\mathrm{Br} J$ Cancer. 2005;92:252-258.

[20] Yokoyama K, Kamata N, Fujimoto R et al. Increased invasion and matrix metalloproteinase-2 expression by Snail-induced mesenchymal transition in squamous cell carcinomas. Int $J$ Oncol. 2003;22:891-898.

[21] Papkoff J, Aikawa M. WNT-1 and HGF regulate GSK3 beta activity and beta-catenin signaling in mammary epithelial cells. Biochem Biophys Res Commun. 1998;247:851-858.

[22] Guo Y, Zi X, Koontz Z et al., Blocking Wnt/LRP5 signaling by a soluble receptor modulates the epithelial to mesenchymal transition and suppresses met and metalloproteinases in osteosarcoma Saos-2 cells. J Orthop Res. 2007;25:964-971.

[23] Guo Y, Xie J, Rubin E et al. Frzb, a secreted Wnt antagonist, decreases growth and invasiveness of fibrosarcoma cells associated with inhibition of Met signaling. Cancer Res. 2008;68:3350-3360.

[24] Ishibe S, Haydu JE, Togawa A, Marlier A, Cantley LG. Cell confluence regulates hepatocyte growth factor-stimulated cell morphogenesis in a beta-catenin-dependent manner. Mol Cell Biol. 2006;26:9232-9243.

[25] Stemmer V, de Craene B, Berx G, Behrens J. Snail promotes Wnt target gene expression and interacts with beta-catenin. Oncogene. 2008;27:5075-5080.

[26] Vega S, Morales AV, Ocana OH, Valdés F, Fabregat I, Nieto MA. Snail blocks the cell cycle and confers resistance to cell death. Genes Dev. 2004;18:1131-1143.

[27] Reshetnikova G, Troyanovsky S, Rimm DL. Definition of a direct extracellular interaction between Met and E-cadherin. Cell Biol. Int. 2007;31:366-373.

[28] Hiscox S, Jiang WG. Association of the HGF/SF receptor, MET, with the cell-surface adhesion molecule, E-cadherin, and catenins in human tumor cells. Biochem Biophys Res. Commun. 1999;261:406-411.

[29] Maestro R, Dei Tos AP, Hamamori Y et al. Twist is a potential oncogene that inhibits apoptosis. Genes Dev. 1999;13:22072217.

[30] Hjiantoniou E, Anayasa M, Nicolaou P et al. Twist induces reversal of myotube formation. Differentiation. 2008;76:182192.

[31] Yang Z, Zhang X, Gang H et al. Up-regulation of gastric cancer cell invasion by Twist is accompanied by N-cadherin and fibronectin expression. Biochem Biophys Res Commun. 2007;358:925-930.

[32] Sakatani T, Kaneda A, Iacobuzio-Donahue CA et al. Loss of imprinting of Igf2 alters intestinal maturation and tumorigenesis in mice. Science. 2005;307:1976-1978.

[33] Rodrigues CO, Nerlick ST, White EL, Cleveland JL, King ML. A Myc-Slug (Snail2)/Twist regulatory circuit directs vascular development. Development. 2008;135:1903-1911.

Submitted: 15 March, 2010 Accepted after reviews: 7 June, 2010 